DE

M E D I C I N A

T R O P I C A L

$\mathrm{DE}$

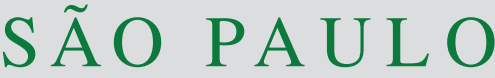

JOURNAL OF THE SÃO PAULO INSTITUTE OF TROPICAL MEDICINE

'Universidade Federal de Goiás, Instituto de Patologia Tropical e Saúde Pública, Goiânia, Goiás, Brazil

2Universidade Federal de Goiás, Unidade Acadêmica Especial de Ciências da Saúde, Jataí, Goiás, Brazil

${ }^{3}$ Universidade Federal de Goiás, Faculdade de Medicina, Hospital das Clínicas, Goiânia, Goiás, Brazil

Correspondence to: Heloisa Ribeiro Storchilo Universidade Federal de Goiás, Instituto de Patologia Tropical e Saúde Pública, Rua 235, s/n, Setor Leste Universitário, CEP 74605-050, Goiânia, GO, Brazil Tel: +55 62 3209-6364

E-mail: lo_storchilo@ hotmail.com

Received: 10 January 2019

Accepted: 15 May 2019

\section{Basic heel prick test: inclusion of screening, diagnosis and criteria for early confirmation of congenital infection by Toxoplasma gondii}

\author{
Heloisa Ribeiro Storchilo ${ }^{(1)}$, Hanstter Hallison Alves Rezende ${ }^{\left({ }^{1}\right.}$, , Taynara \\ Cristina Gomes ${ }^{\circledR 1}$, Jéssica Yonara de Souza ${ }^{(1)}$, Antonio Roberto Gomes \\ Junior ${ }^{(1)}$, Mariza Martins Avelino $^{3}$, Waldemar Naves do Amaral ${ }^{\circledR 3}$, Ana Maria \\ de Castro ${ }^{1}$
}

\section{ABSTRACT}

Toxoplasma gondii can cross the placental barrier, causing fetal infection with potentially severe sequelae. The aim of this study was to evaluate whether the serological screening for toxoplasmosis should be included in the basic neonatal heel prick test in order to establish criteria for the confirmation and/or exclusion of the diagnosis of congenital infection in newborns treated at three public health units in the metropolitan region of Goiania, Goias State, Brazil. Blood samples were collected on filter paper from newborns and later, peripheral blood samples from the mothers and their respective children were obtained to confirm or exclude the diagnosis of suspected congenital infection, by means of an enzyme-linked immunosorbent assay (IgM and $\mathrm{IgG}$ ) and a polymerase chain reaction assay. From a total of 1,159 blood samples collected on filter paper, $43.92 \%$ were reactive to $\mathrm{IgG}$ and $0.17 \%$ to anti-T. gondii IgM and IgG. One hundred and twenty-seven paired samples (mother and child) were collected following consensual protocols for peripheral blood collection. Results obtained from the filter paper and peripheral blood of the newborns were $90.55 \%$ concordant. A comparison of the mother and child blood test results showed agreement regarding the detection of $\mathrm{IgG}$ in $90.48 \%$ of the samples. The parasite DNA was detected in the peripheral blood of one child. In view of the results obtained in this study, the inclusion of the serological screening for toxoplasmosis in the newborn heel prick test proved to be effective for the early detection of congenital T. gondii infection.

KEYWORDS: Serological tests. Neonatal screening. Newborn. Congenital toxoplasmosis. Heel prick test.

\section{INTRODUCTION}

Toxoplasmosis is an infection caused by the protozoan Toxoplasma gondii and is asymptomatic in most immunocompetent individuals. However, vertical transmission can cause a number of clinical manifestations in the fetus, and is among the main causes of morbidity and mortality in the neonatal period ${ }^{1,2} \cdot T$. gondii infects 25 to $30 \%$ of the world's population ${ }^{3}$, and several studies have found a high prevalence of toxoplasmosis in pregnant women in various countries, underscoring the importance of this congenital transmission ${ }^{4,5}$.

In the first trimester, the transmission rate to the fetus is around $10-15 \%$, in the second trimester $22-40 \%$ and in the third trimester it increases to about $68 \%$. The severity of the infection is inversely proportional to the gestational age, and can lead to fetal death in the first trimester of pregnancy. In the second trimester, 
infection may lead to the Sabin's tetrad of symptoms, and in the third trimester of pregnancy the child is usually born asymptomatic and may present with some evidence of the disease a few days, weeks or months after birth ${ }^{7}$.

Prevention strategies for congenital toxoplasmosis adopted by public health systems differ among countries ${ }^{8,9}$. Those with a high prevalence of $T$. gondii infection, such as Brazil, France, Australia and Colombia, have included toxoplasmosis testing in the prenatal screening following different schemes ${ }^{10}$, while countries with a low prevalence of this infection have adopted educational practices and even diagnosis during the neonatal screening ${ }^{11}$.

Primary and secondary prophylactic measures decreased the vertical transmission rate and/or sequelae in infected infants ${ }^{12}$. According to Gomes Filho et al. ${ }^{13}$, toxoplasmosis is considered the second most frequent disease among positive tests detected by the prenatal screening of pregnant women in Goias State, which should serve as a warning to pregnant women who do not undergo proper prenatal care.

The purpose of the neonatal screening by means of the newborn heel prick test is to track and detect pathologies in 3 to 7-day-old newborns. This procedure has included new and more effective diagnostic methods that can identify not only metabolic diseases, but also other types of pathologies such as hematological, infectious and genetic disorders ${ }^{14}$. Thus, the early detection of congenital infections in newborns through the neonatal heel prick test may minimize the shortcomings of the current toxoplasmosis control program, including seroconversion surveillance.

The aim of this study was to perform a serological screening for toxoplasmosis in samples collected on filter paper for the basic neonatal heel prick test provided by the public health system and to establish criteria for the confirmation and/or exclusion of congenital infections at three reference units in the metropolitan region of Goiania, Goias State, Brazil.

\section{MATERIALS AND METHODS}

\section{Selection of patients}

This is a prospective and descriptive study, carried out from May 2015 to April 2017. Newborns between three to seven days of life were screened by the heel prick test in three public health units in the metropolitan region of Goiania, Goias State, namely: Maternity Hospital Dona Iris (HMDI), Hospital das Clinicas of the Federal University of Goias (HC-UFG) in Goiania, Goias State, and Center for Comprehensive Attention to New Age Health (CAIS-CNE) in Aparecida de Goiania, Goias State.
This study was approved by Plataforma Brasil on February the $11^{\text {th }} 2015$, under the Decision $N^{\circ} 943.441$.

\section{Blood samples collection}

Blood samples were collected from the newborns after the informed consent was signed by their parents or the person in charge.

\section{Filter paper sample}

When performing the neonatal heel prick test, the collected blood sample was absorbed by a $3 \mathrm{~cm}^{2}$ Wathman filter paper $\mathrm{N}^{\circ} 1$. The filter paper cards were identified, dried at room temperature and sent to Laboratorio da Relacao Parasito Hospedeiro of the Universidade Federal de Goias (LAERPH-UFG) to perform the serological test by an enzyme immunoassay (ELISA) for the detection of anti-T. gondii antibodies (IgM and $\operatorname{IgG})$.

\section{Peripheral blood sample}

After two to four months of blood collection on filter paper, $3 \mathrm{~mL}$ of the infants' peripheral blood were sampled in ethylenediaminetetra-acetic acid (EDTA) tubes to confirm the serological results and to perform the polymerase chain reaction (PCR). A blood sample from their respective mothers was collected to compare the serological results.

The established criteria for peripheral blood collection were positive filter paper results for IgM and/or for IgG (optical densities $>3$ ), detected by the ELISA. The cutoff point was established by the average of the first 100 samples that were reagent for anti-T. gondii $\operatorname{IgG}$ on filter paper, with indices $\geq 3$. Polymerase chain reaction (PCR) tests were performed only on samples from infants in whom congenital infection was suspected.

Infants presenting one or more of the following criteria were considered congenitally infected: presence of anti-T. gondii IgM antibodies, IgG antibody concentrations with indices significantly higher than their mothers, positive PCR (when performed as a complementary test).

\section{ELISA serological test}

For anti-Toxoplasma IgM and $\operatorname{IgG}$ antibodies detection, the ELISA commercial kit Bioelisa-Bioclin ${ }^{\circledR}$ (Quibasa, Santa Branca, Belo Horizonte, Brazil) was used. The procedure was performed according to the manufacturer's instructions. Blood samples were diluted in microplates 1: 100 sensitized with T. gondii antigens. After incubation and 
microplates washing, the conjugate was added and a new incubation and washing step were performed. Subsequently, the chromogenic substrate and the stop solution were added and the absorbance of each sample was obtained in the KHB ST-360 ${ }^{\circledR}$ microplate reader.

For the serological examination of blood samples collected on filter paper, the following adaptation was made: a $5 \mathrm{~mm}$ diameter disc was used instead of the blood sample. Then, discs were placed on microplates and eluted with the sample diluent provided by the commercial kit, in a 1:100 ratio. After incubation, disks were removed, microplates washed and the other steps were performed according to manufacturer's instructions.

\section{DNA extraction and polymerase chain reaction (PCR)}

Molecular examination was performed on all peripheral blood samples from newborns presenting with positive IgM and/or IgG in the serological tests as well as those with undetermined $\mathrm{IgG}$ results. DNA extraction was carried out according to the Biopur ${ }^{\circledR}$ commercial kit protocol (Mobius Life Science, Pinhais, Parana, Brazil). Briefly, $200 \mu \mathrm{L}$ of the leukocyte layer obtained by centrifugation of peripheral blood samples were used.

PCR was performed in a final volume of $25 \mu \mathrm{L}$ containing $10 \mathrm{mM}$ TRIS HCl (pH 9.0), $3.5 \mathrm{mM} \mathrm{MgCl}, 0.2 \mathrm{U}$ of Taq DNA Polymerase, $0.5 \mathrm{mM}$ of dNTP, 50 pmol of each primer and $2 \mu \mathrm{L}$ of template DNA. The amplification program consisted of an initial denaturation step at $94^{\circ} \mathrm{C}$ (5 min), 35 cycles of denaturation at $94{ }^{\circ} \mathrm{C}(1 \mathrm{~min})$, annealing at $62^{\circ} \mathrm{C}$ (1 min) and extension at $72{ }^{\circ} \mathrm{C}(1 \mathrm{~min})$, followed by a final extension at $72{ }^{\circ} \mathrm{C}$ for $10 \mathrm{~min}$. The primer pairs used were: Toxo-B5 (5'-TGAAGAGAGGAAACAGGTGGTCG-3') and Toxo-B6 (5'-CCGCCTCCTTCGTCCGTCGTA-3') $)^{15,16}$. PCR products were analyzed on $6 \%$ polyacrylamide gels stained with silver nitrate ${ }^{17}$. All the PCR steps were monitored by positive and negative controls. Positive controls came from the RH (highly virulent) and the ME-49 (less virulent ) strains, and the negative ones consisted of biological materials from individuals who tested negative in serological and parasitological tests.

Each PCR reaction was performed in duplicate, and in case of discordant results, a new reaction was performed to confirm the result.

\section{RESULTS}

\section{Serologic screening on filter paper}

A total of 1,159 blood samples were collected on filter paper from newborns between 3 and 7 days of life. The presence of anti- $T$. gondii IgG antibodies were detected in $43.92 \%(509 / 1,159)$ of the samples. The results were undetermined for $\operatorname{IgG}$ in $1.55 \%(18 / 1,159)$ of the samples, and the presence of anti-T. gondii IgM and IgG antibodies was detected in $0.17 \%(2 / 1,159)$ of the samples, by ELISA.

Filter paper serological analysis and comparison with peripheral blood samples conventional serology

Of the 511 blood samples collected on filter paper that were reactive to $\operatorname{IgG}, 61.25 \%$ (313/511) presented an ELISA absorbance index $\geq 3$. From these reactive samples, 126 pairs (mother and infant) of peripheral blood samples were collected, in one case, only the peripheral blood of the newborn was collected, totaling 253 samples.

The comparison of the results obtained by serology performed on filter paper (first week of life) with the results obtained by the analysis of the peripheral blood performed two to four months after birth revealed that there was concordance in the detection of $\operatorname{IgM}$ and $\operatorname{IgG}$ in one sample $1 / 127(0,79 \%)$, persistence of $\operatorname{IgG}$ in $115 / 127$ (90.55\%) infants, undetermined IgG results in 2/127 (1.57\%) and disagreement of results in 9/127 (7.09\%) infants.

Two of the filter paper blood samples were $\operatorname{IgM} / \mathrm{IgG}$ positive. However, peripheral blood collected before two months of age confirmed the presence of $\operatorname{IgM} / \mathrm{IgG}$ in only one of the peripheral blood samples, while the other sample was only positive for $\operatorname{IgG}$ according to the optical density found in the ELISA test.

Comparison of the serological profiles of peripheral blood from seropositive newborns and from their respective mothers

As mentioned earlier, peripheral blood samples were collected from 126 pairs (mother and infants), totaling 252 samples. Results were compared and are presented in Table 1.

It was possible to observe that in $90.48 \%$ of the samples, the comparison of the serological results between mother and infant were concordant even after two to four months after the tests performed on filter paper.

As for the two samples collected on filter paper that tested positive for anti-T. gondii $\operatorname{IgM}$ and $\mathrm{IgG}$, in the first case, the infant's peripheral blood sample showed a positive result only for anti-T. gondii IgG. In the second case, the results obtained from the infant's peripheral blood sample were consistent with those of the sample collected on filter paper, but, unfortunately, a peripheral blood sample could not be obtained from the mother because she left the study. 
Table 1 - Comparison of serological results (ELISA) for toxoplasmosis of 126 pairs (mother-infant) of peripheral blood samples collected from infants between two to four months after birth and their respective mothers, in three public health units in the metropolitan region of Goiania, Goias State.

\begin{tabular}{|c|c|c|}
\hline \multirow{2}{*}{ Results } & \multicolumn{2}{|c|}{ Mother + Baby } \\
\hline & $\mathrm{N}^{\circ}$ & $\%$ \\
\hline $\begin{array}{l}\lg M / \lg G \text { reactive (mother) and } \lg G \\
\text { reactive (infant) }\end{array}$ & 01 & 0.79 \\
\hline Mother and infant reactive (lgG) & 114 & 90.48 \\
\hline $\begin{array}{l}\text { Reactive mother and undetermined } \\
\text { infant (IgG) }\end{array}$ & 02 & 1.59 \\
\hline Nonreactive mother and infant (IgG) & 04 & 3.17 \\
\hline $\begin{array}{l}\text { Reactive mother and non-reactive } \\
\text { infant (IgG) }\end{array}$ & 05 & 3.97 \\
\hline Total samples & 126 & 100 \\
\hline
\end{tabular}

Note: IgM: Immunoglobulin M; IgG: Immunoglobulin G; N: absolute number; \%: Percentage

\section{Complementary test on peripheral blood samples of infants in whom congenital infection was suspected}

In this study, $7.82 \%(09 / 115)$ of peripheral blood samples from infants showed significantly higher antibody concentrations than those of their mothers. A higher $\operatorname{IgG}$ antibody concentration than that detected in the mother is one of the criteria proposed to indicate the presence of congenital infection, so that these infants will be serologically monitored in their first year of life to confirm or exclude the congenital infection.

All the peripheral blood samples from infants whose $\mathrm{IgG}$ results were positive and undetermined were subjected to PCR. This test confirmed the presence of T. gondii DNA in one of the 118 peripheral blood samples analyzed.

The absorbance indices on filter paper (OD 3.85) and the peripheral blood (OD 3.8) in the PCR positive case were constant after the three-month interval between blood collections, highlighting the importance of valuing high optical densities detected by ELISA as indicative of congenital infection, as demonstrated in this case.

\section{DISCUSSION}

Given the high prevalence rates of $T$. gondii infection in pregnant women in several parts of the world, and particularly in Brazil $1^{4,5,18,19}$, the possibility of congenital transmission is a matter for concern for healthcare managers, highlighting the importance of programs to protect pregnant women and of robust criteria for the confirmation and follow-up of women and their infants with suspected active infection ${ }^{20}$. In this study, $44.08 \%$ of the newborns tested positive for IgG on filter paper.

As $\operatorname{IgG}$ is an immunoglobulin that crosses the placental barrier, we can infer that the prevalence of chronically infected pregnant women in this study was $44.08 \%$, a rate that is more elevated than in other countries: $17.3 \%$ in the United Kingdom ${ }^{21}$ and $15.62 \%$ in Mexico ${ }^{22}$. However, in Brazil, this rate was lower than the data found in the cities of Gurupi, Tocantins State $(68.7 \%)^{5}$, Sao Jose do Rio Preto, Sao Paulo State $(64.4 \%)^{18}$, Caxias, Maranhao State $(77.9 \%)^{19}$ and Goiania, Goias State $(68.3 \%)^{23}$.

According to the results of this study, it was also inferred that $55.91 \%(648 / 1,159)$ of the mothers were seronegative to T. gondii, and were considered at risk to acquire a primary infection, demonstrating the need of a close follow-up in future pregnancies ${ }^{24}$.

The early detection of congenital infections in infants is of paramount importance in the diagnosis and prognosis of toxoplasmosis. In our study, we detected two newborns $(0.17 \%)$ with anti-T. gondii $\operatorname{IgM}$ antibodies, and this immunoglobulin is a marker of acute infection, thus confirming the occurrence of vertical transmission, since this class of immunoglobulins does not cross the placental barrier $^{25}$.

This result shows, even in a population not considered at risk, that the detected congenital transmission was higher than the one found in the studies by Bichara et al. ${ }^{26}$, in Belem, Para State, in which IgM was detected in only one of the 1,000 newborns investigated by ELISA on filter paper, and Schmidt et al. ${ }^{27}$, in Denmark, who detected IgM in 55 of the 262,912 samples.

Data reported in the literature demonstrate different rates of congenital transmission that are usually detected during the prenatal monitoring of pregnant women considered at risk $^{5,28}$. The detection of infection through the neonatal heel prick on asymptomatic newborn infants born to chronically infected mothers is an excellent alternative for health care programs. In this study, the validation of the serological screening of blood on filter paper corroborates the findings of Paul et al..$^{29}$, who detected anti-T. gondii IgM antibodies on filter paper by ELISA, with $95 \%$ sensitivity and $99.9 \%$ specificity compared to the conventional serology

Despite the high sensitivity and specificity of ELISA, the heel prick test may not cover all cases of congenital toxoplasmosis. The non-detection of IgM antibodies, can occur due to the period of gestation in which the transmission took place and the treatment prescription during pregnancy ${ }^{30,31}$.

Despite the importance of confirming and/or excluding results obtained on filter paper, the difficulties of communication with the parents of the newborns are 
noteworthy, as well as their lack of interest in participating in the study and authorizing a second blood sampling.

Therefore, $40.57 \%$ (127/313) of peripheral blood samples were collected under the guise of a new blood sample. This enabled us to analyze the concordance between the serological results for toxoplasmosis of blood samples collected on the filter paper with the peripheral blood results of the infants. In fact, 9.44\% (12/127) of the samples showed discordant results, which may be justified by the half-life of $\operatorname{IgM}$ and $\operatorname{IgG}$ antibodies, since peripheral blood samples were collected within three months after collection of blood on filter paper. According to the work of Lago et al. ${ }^{30}, 19.6 \%$ of newborns with congenital toxoplasmosis confirmed by detection of IgM antibodies in the first week of life, presented negative results after 30 days of life.

Even so, it was possible to demonstrate the high percentage of $\operatorname{IgG}$ antibodies (89.76\%) in peripheral blood samples and blood collected on filter paper. This can be attributed to the sensitivity of the test (61.1-99.3\%), corroborating the effectiveness of the ELISA test on filter paper and the high reproducibility of the technique ${ }^{32}$.

Regarding the comparison of the serological results of the mothers and their respective offspring, five paired samples showed that mothers were IgG positive and their newborns were negative. These cases can be explained by the decrease in the levels of these antibodies passively transmitted from the mothers to the newborns since IgG has a half-life of four weeks and peripheral blood samples were collected up to four months after the first blood sampling on filter paper ${ }^{33}$.

One way to confirm the diagnosis of congenital toxoplasmosis is via serological testing performed during the infant's first year of life, when it is possible to observe the increase in $T$. gondii IgG antibodies. Significant higher levels of antibodies in the infant than in the mother may be indicative of congenital infection. In our study, these serological characteristics were detected in $7.82 \%$ of the infants, demonstrating the need of the infant's monitoring to confirm or exclude the congenital infection until the end of the first year of life ${ }^{34,35}$.

Another criterion for the confirmation of congenital infection is the detection of $T$. gondii DNA by molecular techniques. These are important tools to diagnose toxoplasmosis of immunocompromised patients, congenital infections and ocular toxoplasmosis ${ }^{36}$. However, the PCR technique is employed mainly in the prenatal diagnosis on amniotic fluid samples of pregnant women with serological evidence of primary infection, and has shown $100 \%$ specificity and $98 \%$ sensitivity with the use of this biological material ${ }^{36,37}$.
In this work, $T$. gondii DNA was detected by PCR in the peripheral blood of a child that presented constant optical densities in the serum analysis (OD 3.85) three months after the blood collection on filter paper (OD 3.80). This was a noteworthy finding, since the serum levels of endogenous IgG produced by infected infants persist or increase after birth. However, $\operatorname{IgG}$ levels usually decline during the first months of life, even in infected infants, due to the decrease in maternal antibodies. Thus, congenital infection in infants that are not undergoing treatment can only be excluded when anti-T. gondii IgG antibodies are absent. In the treated infant, IgG may disappear and rise again after discontinuation of treatment ${ }^{38}$.

\section{CONCLUSIONS}

The diagnosis of congenital toxoplasmosis is complex and depends on several factors, particularly those pertaining to the gestational age in which the vertical transmission has taken place. Most infected infants are asymptomatic, making their identification even more difficult, requiring complementary techniques, especially PCR, as demonstrated in this study. Healthcare programs for pregnant women and newborns are important and should be standardized throughout the country. In view of the results obtained in this study, the inclusion of a serological screening for toxoplasmosis in the basic neonatal heel prick test, which is already available in Brazil's National Health Service (SUS) for other infections, has proved to be effective for the early detection of $T$. gondii.

\section{AUTHORS' CONTRIBUTIONS}

Heloisa Ribeiro Storchilo: responsible for the contact with administrators of the health units included in the study, sample collection, experimental procedures, data analysis and writing of the scientific article. Hanstter Hallison Alves Rezende: responsible for the contact with administrator of the Centro de Atenção Integral à Saúde (CAIS) Nova Era (CNE) in Aparecida de Goiânia, Goiás, sample collection and contribution in writing the scientific article. Taynara Cristina Gomes: responsible for the contact with administrators of the health units included in the study, sample collection and contribution to the writing of the scientific article. Jéssica Yonara de Souza: contributed to the experimental procedure and to the writing of the scientific article. Antonio Roberto Gomes Junior: contributed to the experimental procedure and to the writing of the scientific article. Mariza Martins Avelino: responsible for the medical monitoring of the children who presented conclusive diagnosis of congenital infection and contribution to the 
writing of the scientific article. Waldemar Naves do Amaral: responsible for the medical monitoring of the children who presented conclusive diagnosis of congenital infection and contribution to the writing of the scientific article. Ana Maria de Castro: coordinator and supervisor, acting in all stages of laboratory execution and in the final conception of the research project article.

\section{ACKNOWLEDGMENTS}

We would like to thank the management and the staff of the Dona Íris Maternity Hospital (HMDI), the Clinical Hospital of the Federal University of Goiás (HC-UFG) and the Nova Era Center for Comprehensive Health Care (CNE/CAIS) by the partnership developed throughout this study. We also thank all the patients who participated in this study and the financial support, public call $N^{\circ} 12 / 2013$ - Programa Pesquisa para o SUS: Gestão Compartilhada em Saúde - PPSUS/GO - FAPEG e Aperfeiçoamento de Pessoal de Nível Superior (Capes).

\section{REFERENCES}

1. Yadav RK, Maity S, Saha S. A review on TORCH: groups of congenital infection during pregnancy. J Sci Innov Res. 2014;3:258-64

2. Jones JL, Parise ME, Fiore AE. Neglected parasitic infections in the United States: toxoplasmosis. Am J Trop Med Hyg. 2014;90:794-9.

3. Montoya JG, Liesenfild O. Toxoplasmosis. Lancet. 2004;363: 1965-76

4. Zemene E, Yewhalaw D, Abera S, Belay T, Samuel A, Zeynudin A. Seroprevalence of Toxoplasma gondii and associated risk factors among pregnant women in Jimmatown, Southwestern Ethiopia. BMC Infec Dis. 2012;12:337.

5. Gontijo da Silva M, Clare Vinaud M, Castro AM. Prevalence of toxoplasmosis in pregnant women and vertical transmission of Toxoplasma gondii in patients from basic units of health from Gurupi, Tocantins, Brazil, from 2012 to 2014. PLoS One. 2015;10:e0141700.

6. Kravetz J. Congenital toxoplasmosis. BMJ Clin Evid. 2013;2013: 0906.

7. Kompalic-Cristo A, Britto C, Fernandes O. Diagnóstico molecular da toxoplasmose: revisão. J Bras Patol Med Lab. 2005;41:22935 .

8. Gilbert RE, Gras L, Wallon M, Peyron F, Ades AE, Dunn DT. Effect of prenatal treatment on mother to child transmission of Toxoplasma gondii: retrospective cohort study of 554 motherchild pairs in Lyon, France. Int J Epidemiol. 2001;30:1303-8.

9. Ho-Yen DO. Toxoplasmosis. Medicine. 2009;37:665-7.
10. Gómez-Marín JE. Congenital toxoplasmosis in South American children. Sci Med (Porto Alegre). 2010;20:103-7.

11. Montoya JG, Rosso F. Diagnosis and management of toxoplasmosis. Clin Perinatol. 2005;32:705-26.

12. Lopes-Mori FM, Mitsuka-Breganó R, Capobiango JD, Inoue IT, Reiche EM, Morimoto HK, et al. Programs for control of congenital toxoplasmosis. Rev Assoc Med Bras. 2011;57:594-9.

13. Gomes Filho C, Macedo Filho JV, Minuzzi AL, Gomes MM, Luquetti AO. Detecção de doenças transmissíveis em gestantes no estado de Goiás: o teste da mamãe. Rev Patol Trop. 2016;45:369-86.

14. Brasil. Ministério da Saúde. Secretaria de Assistência à Saúde. Coordenação-Geral de Atenção Especializada. Manual de normas técnicas e rotinas operacionais do programa de triagem neonatal. Brasília: Ministério da Saúde; 2002.

15. Burg JL, Grover CM, Pouletty P, Boothroyd JC. Direct and sensitive detection of a pathogenic protozoan, Toxoplasma gondii, by polymerase chain reaction. J Clin Microbiol. 1989;27:1787-92.

16. Cristina N, Liaud MF, Santoro F, Oury B, Ambroise-Thomas P. A family of repeated DNA sequences in Toxoplasma gondii: cloning, sequence analysis, and use in strain characterization. Exp Parasitol. 1991;73:73-81.

17. Santos FR, Pena SD, Epplen JT. Genetic and population study of a Y-linked tetranucleotide repeat DNA polymorphism with a simple non-isotopic technique. Hum Genet. 1993;90:655-6.

18. Mattos CC, Spegiorin LC, Meira CS, Silva TC, Ferreira AI, Nakashima F, et al. Anti-Toxoplasma gondii antibodies in pregnant women and their newborn infants in the region of São José do Rio Preto, São Paulo, Brazil. Sao Paulo Med J. 2011;129:261-6.

19. Câmara JT, Silva MG, Castro AM. Prevalência de toxoplasmose em gestantes atendidas em dois centros de referência em uma cidade do Nordeste, Brasil. Rev Bras Ginecol Obstet. 2015;37:64-70.

20. Lindsay DS, Dubey JP. Toxoplasma gondii: the changing paradigm of congenital toxoplasmosis. Parasitology. 2011;138:1829-31.

21. Flatt A, Shetty N. Seroprevalence and risk factors for toxoplasmosis among antenatal women in London: a reexamination of risk in an ethnically diverse population. Eur $\mathrm{J}$ Public Health. 2013;23:648-52.

22. Galvan-Ramirez ML, Troyo R, Roman S, Calvillo-Sanchez C, Bernal-Redondo R. A systematic review and meta-analysis of Toxoplasma gondii infection among the Mexican population. Parasit Vectors. 2012;5:271.

23. Sartori AL, Minamisava R, Avelino MM, Martins CA. Triagem pré-natal para toxoplasmose e fatores associados à soropositividade de gestantes em Goiânia, Goiás. Rev Bras Ginecol Obstet. 2011;33:93-8.

24. Avelino MM, Parada JC, Castro AM, Alves MF, Campos Jr D. Toxoplasma gondii primary infection in pregnant women 
in Goiânia: a seroconversion study. Rev Cien Med Biol. 2009;8:325-33.

25. Remington JS, McLeod R, Thulliez P, Desmonts G. Toxoplasmosis. In: Remington JS, Klein JO, Wilson CB, Baker CJ, editors. Infectious diseases of the fetus and newborn infant. $6^{\text {th }}$ ed. Philadelphia: Elsevier Saunders; 2006. p.947-1091.

26. Bichara CN, Canto GA, Tostes CL, Freitas JJ, Carmo EL, Póvoa $\mathrm{MM}$, et al. Incidence of congenital toxoplasmosis in the city of Belém, Pará State, Brazil. Rev Soc Bras Med Trop. 2012;45:122-4.

27. Schmidt DR, Hogh B, Andersen O, Fuchs J, Fledelius H, Petersen E. The national neonatal screening programme for congenital toxoplasmosis in Denmark: results from the initial four years, 1999-2002. Arch Dis Child. 2006;91:661-5.

28. Avelino MM, Campo s Jr D, Parada JC, Castro AM. Pregnancy as a risk factor for acute toxoplasmosis seroconversion. Eur J Obstet Gynecol Reprod Biol. 2003;108:19-24.

29. Paul M, Petersen E, Szczapa J. Prevalence of congenital Toxoplasma gondii infection among newborns from the Pozna Region of Poland: validation of a new combined enzyme immunoassay for Toxoplasma gondii-specific immunoglobulin A and immunoglobulin $\mathrm{M}$ antibodies. J Clin Microbiol. 2001;39:1912-6.

30. Lago EG, Oliveira AP, Bender AL. Presence and duration of anti-Toxoplasma gondii immunoglobulin $\mathrm{M}$ in infants with congenital toxoplasmosis. J Pediatr (Rio J). 2014;90:363-9.
31. Couvreur J, Thulliez P, Daffos F, Aufrant C, Bompard Y, Gesquière A, et al. In utero treatment of toxoplasmic fetopathy with the combination pyrimethamine-sulfadiazine. Fetal Diagn Ther. 1993;8:45-50.

32. Zhang K, Wang L, Lin G, Sun Y, Zhang R, Xie J, et al. Results of the National External Quality Assessment for Toxoplasmosis Serological Testing in China. PLoS One. 2015;10:e0130003.

33. Dunn D, Wallon M, Peyron F, Petersen E, Peckham C, Gilbert R. Mother-to-child transmission of toxoplasmosis: risk estimates for clinical counselling. Lancet. 1999;353:1829-33.

34. Moncada PA, Montoya JG. Toxoplasmosis in the fetus and newborn: an update on prevalence, diagnosis and treatment. Expert Rev Anti Infect Ther. 2012;10:815-28.

35. Saadatnia G, Golkar M. A review on human toxoplasmosis. Scand J Infect Dis. 2012;44:805-14.

36. Remington JS, Thulliez P, Montoya JG. Recent developments for diagnosis of toxoplasmosis. J Clin Microbiol. 2004;42:941-5.

37. Teixeira LE, Kanunfre KA, Shimokawa PT, Targa LS, Rodrigues JC, Domingues W, et al. The performance of four molecular methods for the laboratory diagnosis of congenital toxoplasmosis in amniotic fluid samples. Rev Soc Bras Med Trop. 2013;46:584-8.

38. Mitsuka-Breganó R, Lopes-Mori FM, Navarro IT, organizadores. Toxoplasmose adquirida na gestação e congênita: vigilância em saúde, diagnóstico e condutas. Londrina: Universidade Estadual de Londrina; 2010. 